\title{
Optimal mate choice patterns in pelagic copepods
}

\author{
Heuschele, Jan; Eliassen, Sigrun; Kiørboe, Thomas
}

\section{Published in:}

Oecologia

Link to article, DOI:

$10.1007 / \mathrm{s} 00442-012-2516-4$

Publication date:

2013

Document Version

Publisher's PDF, also known as Version of record

Link back to DTU Orbit

Citation (APA):

Heuschele, J., Eliassen, S., \& Kiørboe, T. (2013). Optimal mate choice patterns in pelagic copepods. Oecologia, 172(2), 399-408. https://doi.org/10.1007/s00442-012-2516-4

\section{General rights}

Copyright and moral rights for the publications made accessible in the public portal are retained by the authors and/or other copyright owners and it is a condition of accessing publications that users recognise and abide by the legal requirements associated with these rights.

- Users may download and print one copy of any publication from the public portal for the purpose of private study or research.

- You may not further distribute the material or use it for any profit-making activity or commercial gain

- You may freely distribute the URL identifying the publication in the public portal

If you believe that this document breaches copyright please contact us providing details, and we will remove access to the work immediately and investigate your claim 


\title{
Optimal mate choice patterns in pelagic copepods
}

\author{
Jan Heuschele · Sigrunn Eliassen · Thomas Kiørboe
}

Received: 16 February 2012/ Accepted: 12 October 2012

(C) Springer-Verlag Berlin Heidelberg 2012

\begin{abstract}
The importance of sexual selection for the evolution, dynamics and adaptation of organisms is well known for many species. However, the topic is rarely studied in marine plankton, the basis of the marine food web. Copepods show behaviors that suggest the existence of sexually selected traits, and recent laboratory experiments identified some selected morphological traits. Here, we use a 'life history-based' model of sex roles to determine the optimal choosiness behavior of male and female copepods for important copepod traits. Copepod females are predicted to be choosy at population densities typically occurring during the main breeding season, whereas males are not. The main drivers of this pattern are population density and the difference in non-receptive periods between males and females. This suggests that male reproductive traits have evolved mainly due to mate competition. The model can easily be parameterized for other planktonic organisms, and be used to plan experiments about sexual selection.
\end{abstract}

Communicated by Craig Osenberg.

Electronic supplementary material The online version of this article (doi:10.1007/s00442-012-2516-4) contains supplementary material, which is available to authorized users.

J. Heuschele $(\bowtie) \cdot T$. Kiørboe

Centre for Ocean Life, National Institute for Aquatic Resources,

Technical University of Denmark, Kavalergården 6,

2920 Charlottenlund, Denmark

e-mail: janheuschele@gmail.com

J. Heuschele $\cdot$ S. Eliassen

Department of Biology, University of Bergen,

P.O. Box 7803, 5020 Bergen, Norway
Keywords Copepods - Pelagic - Sexual selection · Mate choice Plankton

\section{Introduction}

Sexual selection is an important process for micro- and macro-evolution (Schluter 2001). It is studied extensively in vertebrates and terrestrial invertebrates, but rarely in marine organisms and especially not in plankton. This is astonishing given that marine plankton provides the basis of the marine food web, and that sexual selection are known to influence population dynamics (Kokko and Rankin 2006).

Copepods in particular have the highest accumulated biomass on earth compared to any other species group (Humes 1994). There are several indications of the presence of sexually selected behaviors in different species of copepods (Titelman et al. 2006). These include mate choice-related behaviors such as pre-copulatory mate guarding, copulatory dances, stroking, and mate escape behaviors. In Pseudocalanus elongatus (Kiørboe et al. 2004), Oithona davisae (Kiørboe 2007), and Temora longicornis, females apparently try to avoid matings by performing escape bouts (Doall et al. 1998), which suggests active mate avoidance behavior, which is a form of female mate choice. Recent studies have reported the first experimental evidence of mate choice in several copepod species. Both sexes of Acartia tonsa show a preference for large partners (Ceballos and Kiørboe 2010), which can increase the reproductive success of choosy individuals given the positive correlation of body size and offspring number. In Oithona davisae, young males and females are able to differentiate the age of potential partners, and are more likely to mate with young partners (Ceballos and 
Kiørboe 2011). Whether this is due to active mate choice or due to reduced mating capability in old individuals remains to be seen. Ali et al. (2009) found that the size of females of Eudiaptomus graciloides was inversely related to the number of attached spermatophores when caught in the field. Bigger females seem to be able to choose or escape males, while small females cannot. Thus, not only mate choice and mate competition but also mate coercion may play a role in copepod reproduction.

While the importance of sexual selection is widely recognized, a recent review questions our knowledge of the strength of sexual selection in different environments and conditions (Cornwallis and Uller 2010). Sexual selection is a context-dependent process (Jennions and Petrie 1997), driven by factors like the spatial and temporal distribution of mates (Shuster and Wade 2003), the quality distribution of potential partners, and the possibility to locate and assess mates (Jennions and Petrie 1997). In natural copepod populations, male and female densities vary between and within years, as well as between populations and species (Mauchline 1998). Encounter rates with potential mates are highly variable and depend not only on mate availability but also on physical conditions like water turbulence (Visser et al. 2009). The process of locating a mate is well studied in several species of copepods. Species like T. longicornis or $O$. davisae rely on pheromone cues released by the females to find mating partners (Kiørboe 2007; Doall et al. 1998; Yen et al. 1998). Others like A. tonsa use hydrodynamical cues for mate search (Bagøien and Kiørboe 2004). Typically, males take the active part of searching for females (e.g., Katona 1973), which may increase their mortality relative to the females (Hirst et al. 2010). The swimming pattern during mate search also varies between species and sexes, and is related to the feeding strategies: male copepods that cruise through the water when feeding, or do not feed at all, can search for mates all the time, while the males of ambush-feeding copepods must switch between feeding and mate searching, and adopt very high swimming velocities during search swimming (Kiørboe 2008). The mate availability, described by the operational sex ratio (OSR), is determined by the species-specific details of the reproductive biology such as the animal's ability to store sperm, the ability to remate, and the differential mortalities of males and females. In some species, adult sex ratios are close to be balanced, while in others, males can become a limiting factor for female reproduction (Kiørboe 2007).

The benefit of mate choice also depends on differences between potential mates, but unfortunately little is known about mate quality variation in copepods. Evolutionary fitness can be measured as the lifetime reproductive success of individuals relative to conspecifics. Offspring number is positively correlated with female and male body size in copepods (e.g., Smyly 1968; Maly 1973; Hylstofte
Sichlau and Kiørboe 2011). We therefore suggest that the variance in body length within a population can serve as a proxy for the variance in fecundity, and thus for the potential benefits of being choosy.

Measuring the strength of sexual selection in copepod populations in the field and in the laboratory is difficult because the traits under selection are mostly unknown and the observations of mating behavior is only possible using video recordings. Therefore, we used a life history-based model (Kokko and Monaghan 2001) to explore how mate choosiness change with population density, mate quality, and length of the non-receptive period after matings ('time outs'). This allows us to compare the relative importance of these factors for the strength of sexual selection. Next, we used parameters on four pelagic copepod species to derive expected patterns of mate selectivity and sex roles in these species.

\section{Materials and methods}

\section{Model}

\section{Life history-based model of sex roles}

We consider a copepod mating system in which breeding occurs continuously and males and female alternate between being receptive ('time in') and non-receptive ('time out') to mating. During 'time in' phases $\left(T_{I M}\right.$ and $T_{I F}$ ), individuals are searching for mates and we assume search efficiency to be a function of swimming speed and detection range (see Table 1 for definition of parameters). The rate of encounter with potential mates also depends on population density. During the 'time out' $\left(T_{\mathrm{M}}\right.$ and $\left.T_{F}\right)$, males are replenishing spermatophores and females use stored sperm to fertilize eggs. For simplicity, we assume that sperm from the first male to mate with a female fertilize all her eggs until his spermatophore is empty. Additional matings during this non-receptive period will hence be unsuccessful although males may try to attach spermatophores. The mortality rate may differ in 'time in' $\left(\mu_{\mathrm{IM}}\right.$ and $\left.\mu_{\mathrm{IF}}\right)$ and 'time out' $\left(\mu_{\mathrm{M}}\right.$ and $\left.\mu_{\mathrm{F}}\right)$, which, combined with different durations of the two states, causes sex-specific mortality rates in our model. As a result, the sex ratio may change through the breeding season. In nature, the adult sex ratio can be determined by several other factors besides differential mortality rates; for example, environmental sex determination (ESD) governed by food conditions (Fleminger 1985; Korpelainen 1990; Irigoien et al. 2000) or intersexuality (Gusmao and McKinnon 2009). The cost of breeding is a function of the mortality experienced in the 'time out' phase. For females, the cost of breeding, $C_{F}$, is: 
Table 1 Variables and their meaning

\begin{tabular}{|c|c|c|}
\hline Variable & Description & Unit \\
\hline$\alpha$ & Primary male to female sex ratio & \\
\hline$\beta$ & Operational sex ratio & \\
\hline$\sigma$ & Variance in mate quality & $\mathrm{mm}$ \\
\hline$\mu_{F}$ & Female mortality during 'time out' & day $^{-1}$ \\
\hline$\mu_{M}$ & Male mortality during 'time out' & day $^{-1}$ \\
\hline$\mu_{I F}$ & Female mortality during 'time in' & day $^{-1}$ \\
\hline$\mu_{I M}$ & Male mortality during 'time in' & day $^{-1}$ \\
\hline$c$ & Mate choosiness & \\
\hline$C_{F}$ & Breeding cost for female & \\
\hline$C_{M}$ & Breeding cost for male & \\
\hline$F$ & Fitness of non-choosy individuals & \\
\hline$F_{c}$ & Fitness of choosy individuals & \\
\hline$D$ & Population density & ind $1^{-1}$ \\
\hline$L$ & Female body length & $\mathrm{mm}$ \\
\hline$M$ & Mate encounter rate & ind day ${ }^{-1}$ \\
\hline$p_{M}, p_{F}$ & Proportion of accepted mates & \\
\hline$q_{M}, q_{F}$ & Increase in quality of mates by being choosy & \\
\hline$T_{F}$ & Female 'time out' & days \\
\hline$T_{M}$ & Male 'time out' & days \\
\hline$T_{I F}$ & Female 'time in' & days \\
\hline$T_{I M}$ & Male 'time in' & days \\
\hline$V$ & Mate search volume & $\mathrm{L} \mathrm{day}^{-1}$ \\
\hline$W$ & Lifetime reproductive success & \\
\hline$x_{m F}, x_{m M}$ & Mean length of mates & $\mathrm{mm}$ \\
\hline$x_{c F}, x_{c M}$ & Body length cut off & $\mathrm{mm}$ \\
\hline $\begin{array}{l}x_{c m F}, \\
\quad x_{c m M}\end{array}$ & Mean length of accepted mates & $\mathrm{mm}$ \\
\hline
\end{tabular}

$c_{F}=\mu_{F} \frac{T_{F}}{\left(1+\mu_{F} T_{F}\right)}$

and for males, $\mathrm{C}_{\mathrm{M}}$,

$c_{M}=\mu_{M} \frac{T_{M}}{\left(1+\mu_{M} T_{M}\right)}$

As in the model of Kokko and Monaghan (2001), we use lifetime reproductive success as fitness measure. The number of offspring a female can produce per mating depends on the number of sperm the male transmits in each spermatophore. We assume sperm number to increase linearly with size of the male, and, similarly, that the number of eggs a female produces is a linear function of her length (Hylstofte Sichlau and Kiørboe 2011). We assume that the quality of mates increases linearly with body size (Ceballos and Kiørboe 2010; Hylstofte Sichlau and Kiørboe 2011), and that the length distribution of potential partners is defined by the mean $x_{\mathrm{m}}$ and the standard deviation $\sigma$. Individuals can choose to accept only the largest fraction $p$ of the encountered mates, which give a higher mean length $x_{\mathrm{cm}}$ of accepted mates relative to the population mean $x_{m}$. Using z-scores from a standard normal table we define a set of chosen proportions $p$, and calculate the associated cut off values $x_{\mathrm{c}}$ The average length of a mating partner $x_{\mathrm{cm}}$ can be calculated by:

$x_{c m}=x_{m} \sqrt{\frac{2}{\pi}} \frac{e^{\frac{\left(x_{c}-x_{m}\right)^{2}}{\sigma^{2}}}}{\operatorname{erfc} \frac{\left(x_{c}-x_{m}\right)^{2}}{\sqrt{2} \sigma}}$

where erfc is the complementary error function, and $x_{c}=z(p) \sigma+x_{\mathrm{m}}$.

The fitness benefits from choosing a partner of length $x$ is $F=a x$ given a linear increase in quality. $a$ can be estimated as the slope of the fecundity-length relationship from experimental studies. If $q$ is the relative increase in the quality of the offspring by receiving a fitness of $F_{\mathrm{c}}=a x_{\mathrm{cm}}$ compared to the fitness benefit from choosing randomly the population mean $F=a x_{\mathrm{m}}$, then $q$ will depend only on the ratio $x_{c m} / x_{m}$.

The length of the copepod also determines the encounter rate. The daily mate search volume $V\left(\mathrm{~L} \mathrm{day}^{-1}\right)$ is calculated using the relationship between female body length $L_{\mathrm{F}}$ $(\mathrm{mm})$ and search volume (Kiørboe and Bagoien 2005).

$V=10^{2} L_{F}^{3}$

The encounter rate per individual per day is the product of population density and search volume. In a population with equal numbers of males and females (adult sex ratio $\alpha=1$ ), only half the encounters will be with a potential partner, hence $M=0.5 \mathrm{VD}$.

The adult as well as the operational sex ratio (ratio of receptive males to receptive females) both become biased if mortality rates and length of the 'time in' and 'time out' periods differ between the sexes. The operational sex ratio, $\beta$, is then (Kokko and Monaghan 2001):

$$
\begin{aligned}
\beta= & \frac{1}{2 \mu_{I M}^{2}}\left[M^{2}\left(\alpha C_{F}-C_{M}\right)^{2}+2 \alpha \mu_{I F} \mu_{I M}\right. \\
& \left.+M\left(\alpha C_{F}-C_{M}\right) \sqrt{M^{2}\left(\alpha C_{F}-C_{M}\right)^{2}+4 \alpha \mu_{I F} \mu_{I M}}\right]
\end{aligned}
$$

Female choice can invade if

$C_{F} M \sqrt{\beta}>\mu_{I F} \frac{\left(1-p_{M} q_{M}\right)}{\left(p_{M}\left(q_{M}-1\right)\right)}$

and male choice can invade if

$C_{M} \frac{M}{\sqrt{\beta}}>\mu_{I_{M}} \frac{\left(1-p_{F} q_{F}\right)}{\left(p_{F}\left(q_{F}-1\right)\right)}$

We determine the invasiveness of mate choice strategies for different combinations of population densities, variance in quality, search mortalities and 'time outs'. For each parameter combination, we first calculate the lifetime reproductive success $W$ of all strategies. Female fitness is calculated according to Kokko and Monaghan (2001) as 
$W_{F}=\frac{p_{M} q_{M} M \sqrt{\beta}}{\left(\mu_{I F}+\mu_{I F} \mu_{F} T_{F}+\mu_{F} T_{F} p_{M} M \sqrt{\beta}\right)}$

and male fitness by

$W_{M}=\frac{p_{F} q_{F} M / \sqrt{\beta}}{\left(\mu_{I M}+\mu_{I M} \mu_{M} T_{M}+\mu_{M} T_{M} p_{F} M / \sqrt{\beta}\right)}$

Then, we determine the $W_{\max }$ among all mate choosiness levels ( $p$ from 0.1 to 1 ), and use the correspondent $p$ as the optimal choosiness level strategy for each scenario.

\section{Model parameterization}

We assume a primary adult male to female sex ratio $\alpha$ (when individuals are entering the adult phase) of 1 . In natural copepod populations, sex ratios are often skewed, which may be due to differential mortality during the adult stage, e.g., by predation and senescence (Hirst and Kiørboe 2002), or other factors such as environmental sex determination (Korpelainen 1990). In the model, we assume that augmented male mortality during mate search ('time in', $T_{I M}$ ) is the main reason for a female-biased sex ratio in the population. As a result, changes in sex ratio always come along with changes in search costs, which could potentially reduce male choosiness. In the general analysis, we therefore also consider the optimal choosiness level when males have lower search costs than females (Figs. 1, 2).

To test whether males and females of certain copepod species should be choosy, we parameterized the model using species-specific values as listed in Table 2. Most values are taken from the primary literature, while some originate from recent experiments performed on-board R/V "DANA" during a cruise in the North Sea. Information about natural mortality rates in copepods is rare and difficult to assess from field data (Hirst and Kiørboe 2002). Therefore, we had to rely on data compiled from several studies (Hirst et al. 2010). We used 'overall' mortality rates from the primary literature for female 'time in' and 'out', as well as male 'time out'. We then adjusted the male's mortality during time in so that calculated adult sex ratios (ASR) matched the ones found in natural populations at common population densities. This is done assuming that it is mainly male copepods that are taking the active and dangerous task of searching for mates (e.g., Katona 1973, Tsuda and Miller 1998). The ASR is approximated using the relative times spend 'out' and 'in' and the corresponding mortality rates.
$A S R=\frac{\mu_{I F} \frac{T_{I F}}{\left(T_{I F}+T_{F}\right)}+\mu_{F} \frac{T_{F}}{\left(T_{I F}+T_{F}\right)}}{\mu_{I M} \frac{T_{I M}}{\left(T_{I M}+T_{M}\right)}+\mu_{M} \frac{T_{M}}{\left(T_{I M}+T_{M}\right)}}$

The 'time-in' of females $T_{\mathrm{IF}}$ and males $T_{\mathrm{IM}}$ are the inverse of the encounter rate with perceptive partners, which in turn is a function of the operational sex ratio $\beta$

$T_{I F}=\frac{1}{p_{M} M \sqrt{\beta}}$

and

$T_{I M}=\frac{1}{p_{F} M / \sqrt{\beta}}$

We calculated the choosiness for a range of combinations of population densities, time-outs and degrees of variation of the partner population. For each species, we analyzed the effect of different variation $(\sigma)$ in the partner's quality on the direction and strength of sexual selection, as these vary during the breeding season. We standardized the approach using the coefficient of variation $(C V)$ in mate quality to be able to compare between species. The values of $C V$ ranged from 0.01 to 0.1 , as observed in natural populations (see Table 2). We define mate choosiness as $c=(1-p)$ when $p$ is the accepted proportion of the partner population.

\section{Results}

Main drivers of sexual selection

We predict that mate choice in pelagic copepods follows the common pattern where females are choosy and males mate with the first receptive female they find (Figs. 1, 2). Population density and the 'time out' of females are the main determinants of the strength of female mate choice in copepods within a biologically relevant parameter space. If population densities are low or the 'time out' of females approaches that of males, females become less choosy (Fig. 1a, b). Both factors influence the number of receptive mates, which in turn ultimately limits the potential for sexual selection.

Male limitation will reduce female choosiness at low encounter rates. Female-biased sex ratios, due to high mate searching costs in males, have a limited effect on female choosiness in our model (Fig. 1c). At the same time, mate searching costs have little effect on male choosiness (Fig. 2c), and remain low even when search mortality of males falls below that of females. Longer female 'time outs' compared to males reduces the time of females to encounter a male with developed spermatophores. Once 


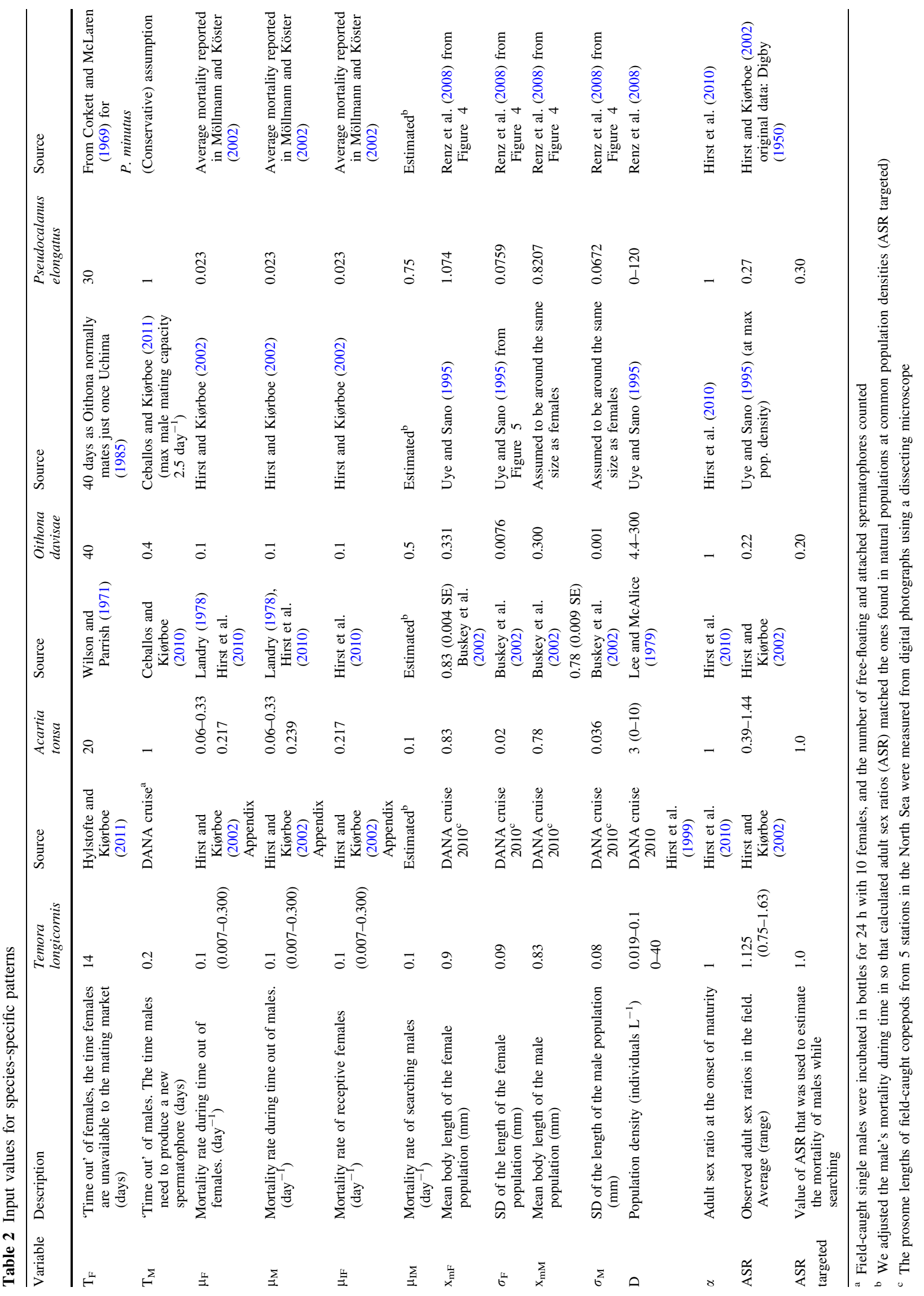


Fig. 1 Optimal female mate choosiness level (mean \pm SD) taken over all other factor combinations as a function of a population density, $\mathbf{b}$ duration of female non-receptivity (time out), c male searching mortality, and $\mathbf{d ~ C V}$ of male quality.

Constant parameter values:

$T_{M}=1$ day; $\mu_{M}, \mu_{F}$,

$\mu_{I F}=0.1$ day $^{-1} ; \alpha=1$; male and female length $=1.0 \mathrm{~mm}$.

Varied parameter values: $\mu_{I M}=0.05-0.55 \mathrm{day}^{-1}, C V$ of male quality $=0.01-0.13$,

$T_{F}=1-3$ days;

$D=0.001-10.03$ ind $\mathrm{L}^{-1}$

Fig. 2 Optimal male choosiness level (mean \pm SD) taken over all other factor combinations as a function of a population density, $\mathbf{b}$ duration of female non-receptivity (time out), c male searching mortality, and $\mathbf{d} \mathrm{CV}$ of male quality.

Constant parameter values:

$T_{M}=1$ day; $\mu_{M}, \mu_{F}$,

$\mu_{I F}=0.1 \mathrm{day}^{-1} ; \alpha=1$; male and female length $=1.0 \mathrm{~mm}$. Varied parameter values: $\mu_{I M}=0.05-0.55 \mathrm{day}^{-1}, \mathrm{CV}$ of female quality $=0.01-0.13$, $T_{F}=1-3$ days;

$D=0.001-10.03$ ind $\mathrm{L}^{-1}$
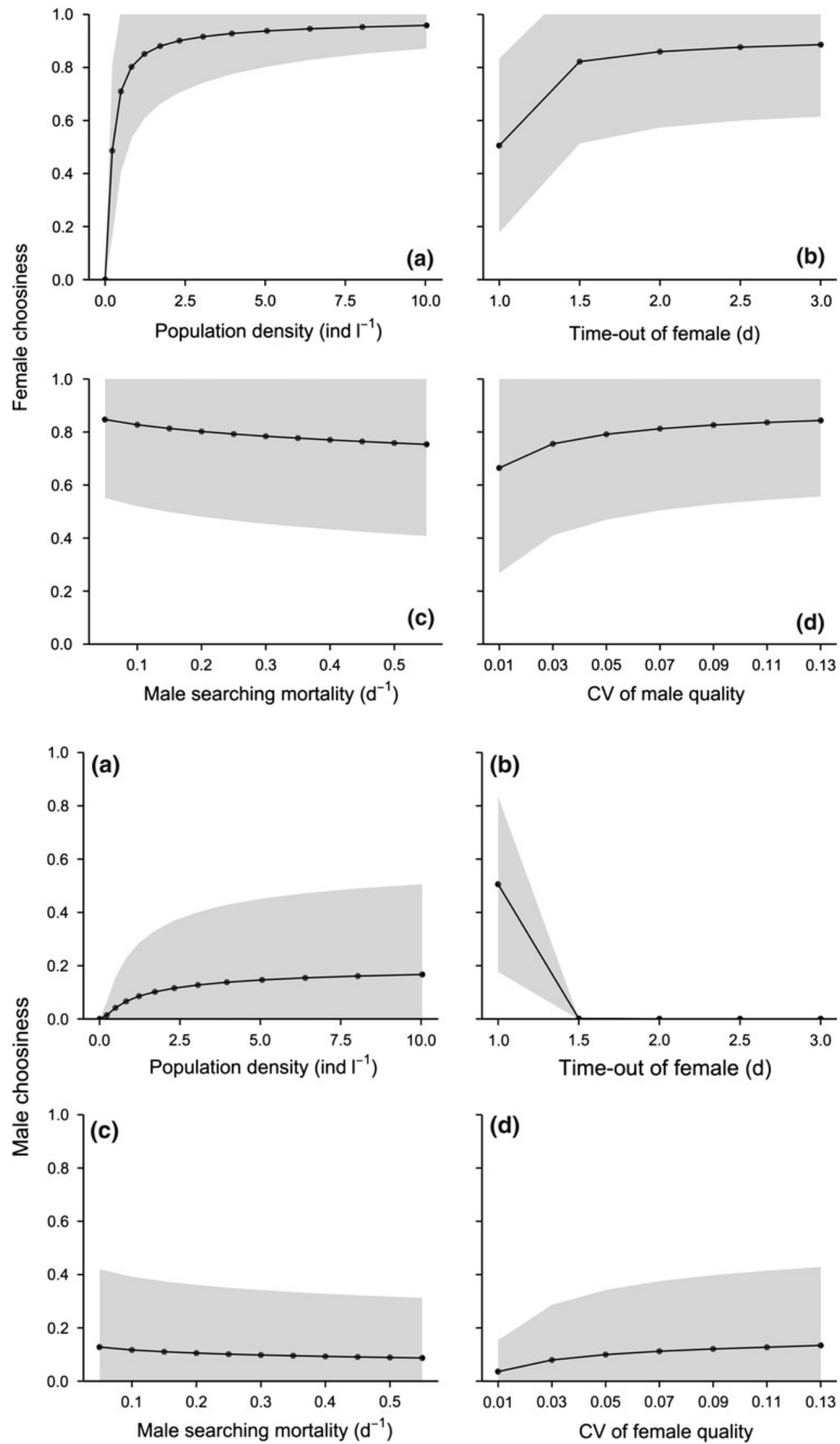
there are enough potential mates, the variance in mate quality determines the strength of mate choice (Fig. 1d). Obviously, if there is no variance in mate quality, then individuals would not be choosy. However, it is reasonable to assume that there will always be at least some variance in mate quality in natural populations.

The larger differences in 'time-out' between males and females suppress any male choosiness (Fig. 2b). Only if male and female 'time outs' are similar, may other factors lead to the expression of male choice. However, in copepods, male time outs are always shorter than those of females (see Table 2), hence male choice is unlikely to evolve in natural copepod populations.

\section{Species-specific patterns}

In Fig. 3, we show optimal choosiness values for different degrees of variance in mate quality and population densities for four different species, which represent different mating strategies. For all four species, the model predicts that males should not be choosy, which is primarily caused by the time out difference between males and females. Temora longicornis, Acartia tonsa, and Pseudocalanus elongatus show similar female choosiness patterns, characterized by choosiness at low population densities $\left(<0.25\right.$ ind $\left.\mathrm{L}^{-1}\right)$. P. elongatus is the biggest of all four tested species, which means that high encounter rates can be maintained even at very low population densities. In contrast to that, $O$. davisae, the smallest species, is predicted to be choosy only if population densities are higher $\left(<10\right.$ ind $\left.\mathrm{L}^{-1}\right)$ and the variance in mate quality is more important in determining the strength of selection.

\section{Discussion}

\section{General points}

Encounter rates, variance in mate quality, and difference in time outs are the main determinants of the strength of sexual selection in this model (Kokko and Monaghan 2001). The variation in the first two factors is big within and between copepod populations and species, assuming that differences in body length represent differences in quality within species. Our study shows a general pattern in copepods with choosy females and non-choosy males.

While information about male mating rates are rare, the few which have been reported show that males are able to produce and deploy more than one spermatophore per day (Ceballos and Kiørboe 2011; Ceballos et al., unpublished data; Ianora et al. 1999), whereas females do not need to be remated for several days or never during their lifetime (i.e., Ceballos and Kiørboe 2011; Hylstofte and Kiørboe 2011;
Wilson and Parrish 1971). Therefore, especially at high population densities, females of all species are predicted to be choosy. At such densities, even a low variance in the quality of potential mates is sufficient to favor choosy females (Fig. 1). However, a combination of low population density and low variance in quality will increase the costs of being choosy and exceed the possible gains of having offspring from high quality partners.

\section{Species and strategies}

Based on differences in their feeding behavior, we might expect costs of mate search to vary in the four copepod species. Copepods that move while feeding ( $T$. longicornis and A. tonsa) can simultaneously search for mates, while ambush-feeders (O. davisae) need to spend dedicated time searching for mates (Kiørboe 2008). Assuming that movement increases encounters with predators through increased hydrodynamic signals and encounter speeds, the latter may face an elevated mortality risk when engaging in mate search (Kiørboe and Visser 1999). Our analysis, however, predicts only small differences in female choosiness among the four copepod species (Fig. 2). Adult males of $P$. elongatus do not feed at all and hence devote all their efforts to mate searching (Corkett and McLaren 1978), but our analysis indicates that females can still afford high mate choosiness even at low population densities.

As in the general analysis, the body size of a species, which determines its encounter rate (Eq. 4), and the variance in mate quality are the most important factors determining the strength of mate choice. At low population densities, small copepods like $O$. davisae should be less choosy than the larger copepod species. Due to their small size, encounter rates are drastically reduced compared to bigger species. However, the abundance of planktonic organisms generally varies inversely with their size (Sheldon et al. 1972; Rodriguez and Mullin 1986), and typical densities of $O$. davisae can approach 300 individuals per liter (Uye and Sano 1995). This means that typical population densities exceed by far the threshold densities that are predicted for female choosiness in our model. Hence, higher population densities balance the reduction of search capacity due to the smaller size, and the intensity of female mate choice can be expected to be similarly high in small and big copepods (Fig. 3).

The role of males

It is remarkable that copepod males are not predicted to be choosy in natural conditions, despite their costly investment in spermatophores. In laboratory experiments, males showed choosiness for large-sized females (Ceballos and Kiørboe 2010). In agreement, male choosiness is predicted 


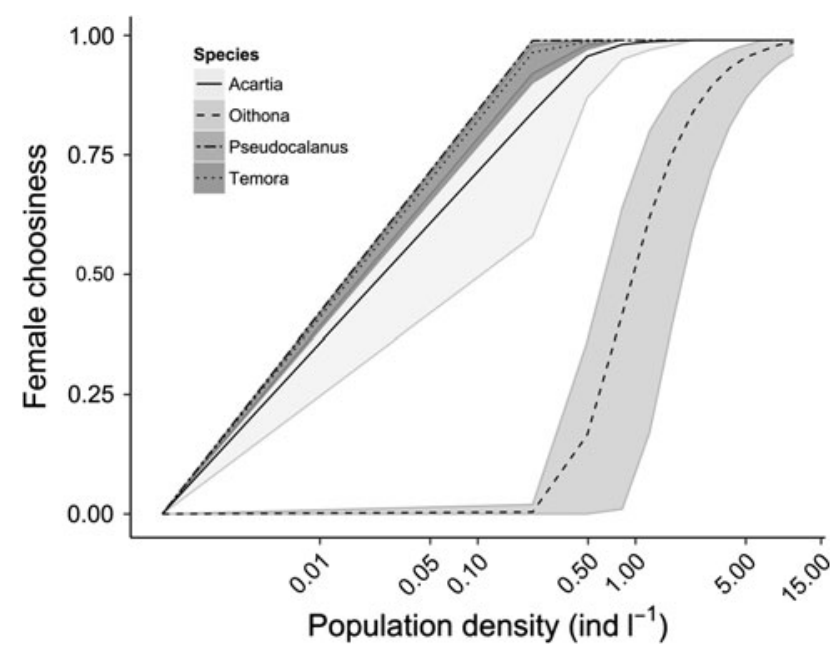

Fig. 3 Female mate choosiness in four copepod species (Acartia tonsa, Temora longicornis, Oithona davisae, Pseudocalanus elongates) as a function of population density (presented on a log scale to the base 10). Female choosiness is expressed as the optimal fraction of the male population to mate (mean \pm upper and lower choosiness limits). Parameter values are taken from Table 2. Varied parameter values: $C V$ of male quality $=0.01-0.10$

by our model at the skewed ASR in the experiments by Ceballos and Kiørboe (2010) (Fig. 4). The model assumes a constant resupply of potential partners, which is not given in the experiment of Ceballos and Kiørboe (2010). The males' hesitation to mate in the experiment might indicate the insufficient knowledge acquisition about potential partners.

The difference of choosiness in the laboratory versus field populations suggests that competition among males for the few rare receptive females in natural populations

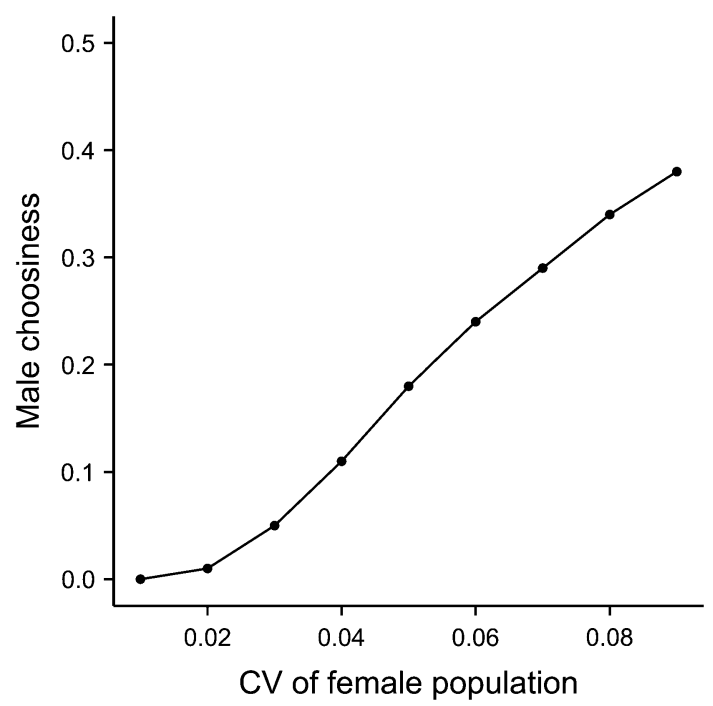

Fig. 4 The optimal male choosiness levels for the experimental conditions described in Ceballos and Kiørboe (2010), which consisted of 4 females and 1 male of Acartia tonsa in a 69-ml bottle overrides mate choice. Hence, distinctive morphological structures of males might have evolved to coerce matings, as suggested by Ali et al. (2009).

Our results show that the intensity of sexual selection and the 'critical density' for the onset of mate choice depends on the variance of quality and the ASR of the male population. Choosing larger males gives females a reproductive advantage (Hylstofte and Kiørboe 2011), as this leads to increased nauplii production in females.

Unfortunately, in population studies, information about male abundance and size is often not reported. Hence, the past and present focus on female traits in plankton ecology may neglect a crucial point of their reproductive biology and, thus, also for the understanding of copepod population dynamics.

Multiple mating and mate choice

Our model assumes that females are not able to use sperm for fertilization from a new male until they run out of sperm from the previous male (e.g., Blades 1977; Anstensrud 1990). While this is the common view in copepodology, it might not hold true for all copepods, as females with several attached spermatophores have been observed in various species (Ali et al. 2009; J.H., personal observation). It is, however, not known whether copepod females can simultaneously use sperm from different males to fertilize their eggs. Females of several insect species are known to engage in multiple matings and receive sperm from several males (Arnqvist and Nilsson 2000). This could make females less choosy when accepting mates, and shift mate choice to later stages in the mating process, for example through cryptic female choice.

Multiple matings can, however, come at additional costs. In fruit flies, the seminal gland products that are transferred during the mating increase female mortality (Fowler and Partridge 1989; Chapman et al. 1995). In the copepod T. longicornis, the repeated exposure to males reduces the longevity of the females (Hylstofte and Kiørboe 2011). Females could therefore benefit from escaping male mating attempts. Such a behavior was used to explain the increased number of spermatophores attached to smaller in comparison to bigger $E$. graciloides females (Ali et al. 2009). Multiple matings are thus a possibility that, on the one hand, might lead to reduced precopulatory female choice, and the evolution of postcopulatory cryptic female choice on sperm from different males (Jennions and Petrie 2000), while, on the other hand, copepod females would still benefit of being choosy, if the act of mating itself reduces female fitness either through the transfer of seminal substances or increased predation risk during coupling. 


\section{Conclusion}

Our study is the first to use a modeling approach to determine the direction and strength of sexual selection by mate choice in planktonic copepods. It predicts strong female choice at typical copepod population densities that occur during the breeding season. Males are predicted to not be choosy under natural conditions. This suggests that the evolution of reproductive traits in males is mainly driven by competition between males for mating opportunities, which can lead to mate guarding tactics as observed in some harpacticoid copepod species (Burton 1985; Shimanaga and Shirayama 2005). Female choosiness can delay the onset of reproduction, and at the same time increase the quality and quantity of offspring, and shows that the link between the relative male and female densities and population densities can be more complicated than previously thought. More knowledge about the behavioral plasticity of mating decisions to changes in mate availability is needed. Our model can facilitate the planning of experimental approaches to sexual selection in copepods and other planktonic organisms.

Acknowledgments Ken Anderson and Uffe Høgsbro Thygesen for help with error-functions; Sara Ceballos and Mie Hylstofte Sichlau for input data, and Øyvind Fiksen for discussions, as well as anonymous referees for constructive comments. J.H. was funded by a DFG Research Fellowship (grant number HE 6050/1-1).

\section{References}

Ali AK, Primicerio R, Folstad I, Liljedal S, Berge J (2009) Morphological correlates of mating frequency and clutch size in wild caught female Eudiaptomus graciloides (Copepoda: calanoida). J Plankton Res 31:389-397

Anstensrud M (1990) Mating strategies of two parasitic copepods [(Lernaeocera branchialis (L.)(Pennellidae) and Lepeophtheirus pectoralis (Müller)(Caligidae)] on flounder: polygamy, sexspecific age at maturity and sex ratio. J Exp Mar Biol Ecol 136:141-158

Arnqvist G, Nilsson T (2000) The evolution of polyandry: multiple mating and female fitness in insects. Anim Behav 60:145-164

Bagøien E, Kiørboe T (2004) Blind dating - mate finding in planktonic copepods. III. Hydrome- chanical communication in Acartia tonsa. Mar Ecol Prog Ser 300:129-133

Blades P (1977) Mating behavior of Centropages typicus (Copepoda: calanoida). Mar Biol 40:57-64

Burton RS (1985) Mating system of the intertidal copepod Tigriopus californicus. Mar Biol 86:247-252

Buskey E, Lenz P, Hartline D (2002) Escape behavior of planktonic copepods in response to hydrodynamic disturbances: high speed video analysis. Mar Ecol Prog Ser 235:135-146

Ceballos S, Kiørboe T (2010) First evidences of sexual selection by mate choice in marine zooplankton. Oecologia 164:627-635

Ceballos S, Kiørboe T (2011) Senescence and sexual selection in a pelagic copepod. PLoS ONE 6:e18870
ChapmanT Liddle L, Kalb J, Wolfner M, Partridge L (1995) Cost of mating in Drosophila melanogaster females is mediated by male accessory-gland products. Nature 373:241-244

Corkett CJ, McLaren IA (1969) Egg production and oil storage by the copepod Pseudocalanus in the laboratory. J Exp Mar Biol Ecol 3:90-105

Corkett CJ, McLaren IA (1978) The biology of Pseudocalanus. Adv Mar Biol 15:1-231

Cornwallis CK, Uller T (2010) Towlatter faces a significantly elevated ards an evolutionary ecology of sexual traits. Trends Ecol Evol 25:145-152

Digby PSB (1950) The biology of the small planktonic copepods of Plymouth. J Mar Biol Assoc UK 29:393-438

Doall M, Colin S, Strickler J, Yen J (1998) Locating a mate in 3D: the case of Temora longicornis. Philos Trans R Soc Lond B 353:681-689

Fleminger A (1985) Dimorphism and possible sex change in copepods of the family Calanidae. Mar Biol 88:273-294

Fowler K, Partridge L (1989) A cost of mating in female fruitflies. Nature 338:760-761

Gusmao LFM, McKinnon AD (2009) Sex ratios, intersexuality and sex change in copepods. J Plankton Res 31:1101-1117

Hirst A, Kiørboe T (2002) Mortality of marine planktonic copepods: global rates and patterns. Mar Ecol Prog Ser 230:195-209

Hirst AG, Sheader M, Williams JA (1999) Annual pattern of calanoid copepod abundance, prosome length and minor role in pelagic carbon flux in the Solent, UK. Mar Ecol Prog Ser 177:133-146

Hirst A, Bonnet D, Conway D, Kiørboe T (2010) Does predation control adult sex ratios and longevities in marine pelagic copepods? Limnol Oceanogr 55:2193-2206

Humes AG (1994) How many copepods? Hydrobiologia 292-293:1-7

Hylstofte Sichlau M, Kiørboe T (2011) Age- and size-dependent mating performance and fertility in a pelagic copepod, Temora longicornis. Mar Ecol Prog Ser 442:123-132

Ianora A, Miralto A, Buttino I, Romano G, Poulet SA (1999) First evidence of some dinoflagellates reducing male copepod fertilization capacity. Limnol Oceanogr 44:147-153

Irigoien X, Obermüller B, Head RN, Harris RP, Rey C, Hansen BW, Hygum BH, Heath MR, Durbinal EG (2000) The effect of food on the determination of sex ratio in Calanus spp.: evidence from experimental studies and field data. ICES J Mar Sci 57:1752-1763

Jennions MD, Petrie M (1997) Variation in mate choice and mating preferences: a review of causes and consequences. Biol Rev 72:283-327

Jennions MD, Petrie M (2000) Why do females mate multiply? A review of the genetic benefits. Biol Rev Cambridge Philos Soc 75:21-64

Katona SK (1973) Evidence for sex pheromones in planktonic copepods. Limnol Oceanogr 18:574-583

Kiørboe T (2007) Mate finding, mating, and population dynamics in a planktonic copepod Oithona davisae: there are too few males. Limnol Oceanogr 52:1511-1522

Kiørboe T (2008) Optimal swimming strategies in mate-searching pelagic copepods. Oecologia 155:179-192

Kiørboe T, Bagoien E (2005) Motility patterns and mate encounter rates in planktonic copepods. Limnol Oceanogr 50:1999-2007

Kiørboe T, Visser AW (1999) Predator and prey perception in copepods due to hydromechanical signals. Mar Ecol Prog Ser 179:81-95

Kiørboe T, Bagoien E, Thygesen U (2004) Blind dating-mate finding in planktonic copepods. II. The pheromone cloud of Pseudocalanus elongatus. Mar Ecol Prog Ser 300:117-128

Kokko H, Monaghan P (2001) Predicting the direction of sexual selection. Ecol Lett 4:159-165 
Kokko H, Rankin D (2006) Lonely hearts or sex in the city? Densitydependent effects in mating systems. Philos Trans R Soc Lond B 361:319-334

Korpelainen H (1990) Sex ratios and conditions required for environmental sex determination in animals. Biol Rev Cambridge Philos Soc 65:147-184

Landry MR (1978) Population dynamics and production of a planktonic marine copepod, Acartia clausii, in a small temperate lagoon on San Juan Island, Washington. Int Rev Ges Hydrobiol 63:77-119

Lee WY, McAlice B (1979) Seasonal succession and breeding cycles of three species of Acartia (Copepoda: calanoida) in a Maine estuary. Estuar Coast 2:228-235

Maly EJ (1973) Density, size, and clutch of two high altitude diaptomid copepods. Limnol Oceanogr 18:840-848

Mauchline J (1998) The biology of calanoid copepods. Academic, London

Möllmann C, Köster F (2002) Population dynamics of calanoid copepods and the implications of their predation by clupeid fish in the Central Baltic Sea. J Plankton Res 24:959-977

Renz J, Mengedoht D, Hirche H (2008) Reproduction, growth and secondary production of Pseudocalanus elongatus Boeck (Copepoda, Calanoida) in the southern North Sea. J Plankton Res 30:511-528

Rodriguez J, Mullin MM (1986) Relation between biomass and body weight of plankton in a steady state oceanic ecosystem. Limnol Oceanogr 31:361-370

Schluter D (2001) Ecology and the origin of species. Trends Ecol Evol 16:372-380
Sheldon RW, Prakash A, Sutcliffe WH Jr (1972) The size distribution of particles in the ocean. Limnol Oceanogr 17:327-340

Shimanaga M, Shirayama Y (2005) Precopulatory mate guarding of interstitial Phyllopodopsyllus sp. (Copepoda: harpacticoida) in Otsuchi Bay, Northeastern Japan. Benthos Res 60:39-40

Shuster SM, Wade MJ (2003) Mating systems and strategies. Princeton University Press, Princeton

Smyly WJP (1968) Number of eggs and body size in the freshwater copepod Diaptomus gracilis Sars in the English Lake District. Oikos 19:323-338

Titelman J, Varpe Ø, Eliassen S, Fiksen Ø (2006) Copepod mating: chance or choice? J Plankton Res 29:1023-1030

Tsuda A, Miller C (1998) Mate-finding behaviour in Calanus marshallae Frost. Philos Trans R Soc Lond B 353:713-720

Uchima M (1985) Copulation in the marine copepod Oithona davisae. I. Mate discrimination. Bull Plankton Soc Jpn 32:23-30

Uye S, Sano K (1995) Seasonal reproductive biology of the small cyclopoid copepod Oithona davisae in a temperate eutrophic inlet. Mar Ecol Prog Ser 118:121-128

Visser AW, Mariani P, Pigolotti S (2009) Swimming in turbulence: zooplankton fitness in terms of foraging efficiency and predation risk. J Plankton Res 31:121-133

Wilson D, Parrish K (1971) Remating in a planktonic marine calanoid copepod. Mar Biol 9:202-204

Yen J, Weissburg M, Doall M (1998) The fluid physics of signal perception by mate-tracking copepods. Philos Trans R Soc Lond B 353:787-804 